\title{
Selection of Lentil (Lens culunaris L.) Lines Grown at Different Sowing Dates for Their Precocity and Their Agronomic Performance under Semi-arid Climate of Tunisia
}

\author{
A. Ouji ${ }^{1,2}$, M. Mechri ${ }^{3}$, S. Wassli4 ${ }^{4}$ K. Shiv ${ }^{5}$, M. Kharrat ${ }^{2}$
}

$10.18805 /$ LR-623

\begin{abstract}
Background: In Tunisia, water deficit and heat stress during the end of cycle are more frequent and causes significant yield losses. Selection of short cycle lines could be a good solution to escape the effect of heat and drought during the end of cycle. Furthermore, there is little published information on the effect of the sowing date on yield and its components in lentils. The aim of this study was to investigate the effect of the sowing date on yield and its components of some lentil lines. The best productive and early lines will be selected and therefore proposed for registration in the official catalog of plant varieties. The availability of these varieties to farmers could increase lentil production.

Methods: Sixteen genotypes of lentil out of which 14 were advanced lines and 2 were checks varieties were used in this study. The field experiment was conducted during the 2017-2018 cropping season at Kef research station located in a semi-arid zone in north western Tunisia. Genotypes were sown on December $15^{\text {th }}, 2017$ and February, $7^{\text {th }}, 2018$. Seventeen agro-morphological parameters were recorded.

Result: Based on agro-morphological analysis, lentil lines exhibited considerable genetic variability. Among the tested lines, L3 line seem to be the earliest lines. It showed high yield as well in timely and late sown dates. This line deserves more attention to develop short-cycle and high yielding variety.
\end{abstract}

Key words: Agronomic traits, Lentil (Lens culinaris L.), Precocity, Selection, Semi-arid, Sowing date.

\section{INTRODUCTION}

Lentil (Lens culinaris Medik) is a self-pollinated, annual, cool season and diploid legume with a relatively larger genome size of $4 \mathrm{Gbp}$ (Arumuganathan and Earle, 1991). It is a good source of protein, dietary fibre and essential minerals and therefore, has the potential to be used as a staple food crop for eradicating the hidden hunger (Gautam et al. 2018). Furthermore, lentil contributes to the fertility and improvement of soil structure and to the enhancement of the productivity of cropping systems through the fixation of atmospheric nitrogen through the symbiotic relationship with the bacterium Rhizobium leguminosarum.

In Tunisia, lentils are cultivated in arid and semi-arid areas. In these areas, with low rainfall, this crop could constitute one of the cultural alternatives for enhancing the value of the farm's land. The average yield of this specie is low, fluctuating and remain insignificant. These fluctuations in yields are attributed to abiotic constraints which slow down its development, in particular water deficit during the end of cycle which is more frequent in Tunisia and which causes significant yield losses. Selection of short cycle lines could be a good solution to escape the effect of heat and drought during the end of cycle. Shrestha et al. (2006) reported that in Mediterranean zone, lentil is facing to an intermittent drought during the vegetative growth and terminal drought throughout their reproductive period when temperatures are ever-increasing and rainfall is declining. Shrestha et al. (2006) have shown that water stress during the reproductive
${ }^{1}$ Regional Research/Development Office of Agriculture in Northwest Semi-arid, le kef, Jendouba University, Tunisia.

${ }^{2}$ Field Crop Laboratory, National Institute for Agricultural Research of Tunisia, Ariana, Carthage University, Tunisia.

${ }^{3}$ National Institute for Field Crops (INGC), Bousalem, Tunisia.

${ }^{4} \mathrm{High}$ Institute of Biotechnology of Beja, Jendouba University, Tunisia.

International Center for Agricultural Research in the Dry Areas, Avenue Hafiane Cherkaoui, Rabat 10112, Morocco.

Corresponding Author: A. Ouji, Field Crop Laboratory, National Institute for Agricultural Research of Tunisia, Ariana, Carthage University, Tunisia. Email: ouji_ali@yahoo.fr

How to cite this article: Ouji, A., Mechri, M., Wassli, S., Shiv, K. and Kharrat, M. (2021). Selection of Lentil (Lens culunaris L.) Lines Grown at Different Sowing Dates for Their Precocity and Their Agronomic Performance under Semi-arid Climate of Tunisia. Legume Research. 44(11): 1278-1283. DOI: 10.18805/LR-623.

Submitted: 10-04-2021 Accepted: 18-08-2021 Online: 09-09-2021

phase negatively affects the yield components, in particular the number of flowers, the number of pods, the number of grains per pod as well as the harvest index.

In Tunisia, lentil acquires importance in the national legume improvement program by developing improved high yielding lentil varieties. In addition to varietal selection, research should be directed more towards the development of appropriate cultivation techniques for increasing lentil 
Selection of Lentil (Lens culunaris L.) Lines Grown at Different Sowing Dates for Their Precocity and Their Agronomic...

yields, especially the date and density of sowing. Results of Sen et al. (2016) and Ugwuoke et al. (2021) showed that cultural practices in particular the sowing date and dose and planting distance and seed rate are among the parameters that affect the growth and yield of plants.

Matthews and Caffery (2011), show that an optimum sowing date can maximize yield potential and minimize disease levels. Sowing early can expose the crop to more rain, which can increase the risk of disease. Early sowing date also increases crop biomass, which subsequently increases the risk of lodging. Late sowing date can result in shorter plants, but can reduce vegetative water use and disease exposure. Furthermore, lentils are not competitive with weeds, therefore, the choice of the sowing date will be one of the solutions to solve this problem. The aim of this study was to investigate the effect of the sowing date on yield and its components of some lentil lines. The best productive and early lines will be selected and therefore proposed for registration in the official catalog of plant varieties.

\section{MATERIALS AND METHODS Experimental procedure}

Sixteen genotypes of lentil out of which 14 were advanced lines and 2 were checks varieties were used in this study. These lines were originated from crosses made at ICARDA and were subsequently selected in the national lentil genetic improvement program (Table 1). The field experiment was conducted during the 2017-2018 cropping season at Kef Research Station (INRAT) located in a semi-arid zone in north-western Tunisia. Experiment was laid out in a randomized split-plot design with three replications. Lines were sown at two sowing dates: Timely sown (December $15^{\text {th }}, 2017$ ) and late sown (February, $7^{\text {th }}, 2018$ ). The plot size was 4 rows of $4 \mathrm{~m}$ long and $0.5 \mathrm{~m}$ between rows. The climatic condition of the experimental station is presented

Table 1: Name and pedigree of the tested genotypes.

\begin{tabular}{ll}
\hline Genotypes & Pedigrees \\
\hline FLIP2004-53L & ILL $4400 \times$ ILL 6199 \\
FLIP2012-244L & ILL7711 $\times$ ILL5480 \\
FLIP2013-66L & ILL7121 $\times$ ILL 1005 \\
FLIP2013-15L & ILL8066 $\times$ ILL6024 \\
FLIP2014-25L & ILL9977 $\times$ ILL1005 \\
FLIP2012-232L & LL7617 $\times$ ILL5883 \\
FLIP2012-56L & ILL6024 $\times$ ILL8009 \\
FLIP2014-60L & ILL4605 $\times$ ILL7723 \\
FLIP2012-71L & ILL7949 $\times$ ILL8072 \\
FLIP2003-55L & ILL6783 $\times$ ILL98 \\
FLIP2013-70L & ILL7537 $\times$ ILL7711 \\
FLIP96-15L & ILL 6209 $\times$ ILL 5671 \\
FLIP2012-196L & ILL590 $\times$ ILL8113 \\
FLIP2012-21L & ILL6129 $\times$ ILL1005 \\
Siliana & ILL4400 $\times$ ILL5582 \\
Kef & $78 S 26002($ ILL5882) \\
\hline
\end{tabular}

in (Table 2). Seventeen agro-morphological parameters viz., the plant height at flowering (PHF), biological yield per plant (BYP), number of branches per plant (NBP), number of productive branches per plant (NPBP), first pod level (FPL), number of pods per inflorescence (NPI), number of pods per plant (NPP), pods weight per plant (PWP), number of seeds per pod (NSPo), number of seeds per plant (NSP), grain yield per plant (GYP), straw yield per plant (SY), harvest index $(\mathrm{HI}), 1000$ seed weight (1000SW), grain yield per ha (GY/ha), number of days until flowering (NDF) and number of days until maturity (NDM).

\section{Data analysis}

Data were subjected to analysis of variance. Relationships between traits was investigated using simple correlation coefficients. Data is subjected to a principal component analysis (PCA). These analyses were carried out by the XLSTAT software.

\section{RESULTS AND DISCUSSION}

To determine the magnitude of genetic variation, morphological evaluation is an important step in description and classification of genotypes (Zubair et al. 2007). Analysis of variance of agro-morphological traits showed significant differences between the tested lines for most of traits (Table 3). This indicated that in this set of materials considerable genetic variability exists, which has great significance to the plant breeder as it plays a crucial role in framing a triumphant breeding program as well as improvement of these traits through selection. Diversified germplasm possessing different desirable traits may prove useful for incorporation of these traits in the lentil improvement programme as confirmed by Gautam et al. (2014). Moderate to high variability was observed for the majority of the studied parameters viz., number of days to flowering (87.3-119 days), number of days to maturity (117-166 days), plant height at flowering (19.3-35.3 cm), number of branches per plant (2-8), number of productive branches per plant (1.7-7 branches), first pod level $(11-26.7 \mathrm{~cm})$, number of pods per plant (10.753.7 pods), grain yield per plant (0.2-1.6 g per plant), straw yield per plant (1.3-6.7g per plant), 1000 seeds weight $(29.3$ $-60 \mathrm{~g})$ and harvest index (10-44\%) (Table 4). Furthermore, analysis of variance of agro-morphological traits showed significant effects of sowing date.

Regarding the phenological parameters, analysis of the variance of the number of days at flowering showed a highly significant genotype effect and a sowing date effect. In case of late sowing, the number of days until flowering and the number of days until maturity has been significantly reduced by 19.6 and 38 days, respectively, compared to early sowing. Among the tested lines, L3 line showed a high yield in both timely and late sowing. This line was also seems to be the earliest. This line deserves more attention and will be useful in the choice of parents in variety improvement programs aiming the selection of varieties simultaneously with high yielding and short-cycle. Similar results were observed by 
Selection of Lentil (Lens culunaris L.) Lines Grown at Different Sowing Dates for Their Precocity and Their Agronomic...

Yannick et al. (2014) who showed that the sowing date influenced the number of days to flowering of a variety of cowpea (Vigna unguiculata). Analysis of the variance data showed highly significant genotype and sowing date effects on the number of days to maturity. The precocity of flowering or/and maturity is an important mechanism for escaping drought in a semi-arid climate such as in the Kef-Tunisia climate. This precocity is considered to be an important trait, which has an interesting effect on lentil yields, especially in areas where the distribution of rainfall and temperature variability affect the length of the development cycle. This was confirmed by Voisin and Salon (2004) who showed that in the Mediterranean climate, the plant must flower at the right time to avoid the damage caused by late spring frosts and by drought and high temperatures at the end of the cycle.
Concerning the growth parameters, analysis of the variance of the plant height at flowering, the number of branches per plant and the first pod level showed significant genotype and sowing date effects. Furthermore, results showed that timely sown date produced significantly higher values of growth parameters. These results were confirmed by Abdel-Rahman et al. (2002) who showed that the sowing date affects the plant height and the number of branches per plant. Regarding the yield and its components, results showed significant genotype and sowing date effects for most of these parameters. In this study, the 1000 seed weight which is an important component of the yield, as well as the number of seeds per pod were greatly influenced by the sowing date. Similar results were observed by Turk et al. (2003) who showed that the date of sowing significantly

Table 2: The maximum and minimum temperatures and rainfall recorded at the NRAT-Kef station during the 2017/2018 cropping season.

\begin{tabular}{lcccccccc}
\hline & Nov. & Dec. & Jan. & Feb. & Mar. & Apr. & May. & June \\
\hline Rainfall $(\mathrm{mm})$ & 96.2 & 23.2 & 32.4 & 31.6 & 41.4 & 34.5 & 29 & 4.2 \\
$\mathrm{~T} \min \left({ }^{\circ} \mathrm{C}\right)$ & 6.5 & 3.7 & 4.6 & 3.5 & 6.6 & 9.1 & 12.2 & 15.3 \\
$\mathrm{~T} \max$ & 16.2 & 12.8 & 16.1 & 13.3 & 18.6 & 23.6 & 26.2 & 30.9 \\
\hline
\end{tabular}

Table 3: Analysis of variance for lentil agro-morphological traits.

\begin{tabular}{|c|c|c|c|c|c|c|c|c|c|}
\hline Source & NDF & PHF & NDM & FPL & BYP & NBP & NPBP & NPI & NPP \\
\hline Genotype (G) & $9.95^{* *}$ & $5.33^{* *}$ & $8.03^{* *}$ & $4.20^{* *}$ & $1.34^{\mathrm{ns}}$ & $2.056^{* *}$ & $1.45^{\mathrm{ns}}$ & $1.54^{\mathrm{ns}}$ & $2.65^{*}$ \\
\hline Sowing date (SD) & $1750.22^{* *}$ & $202.31^{* *}$ & $6172.03^{* *}$ & $17.54^{* *}$ & $1.98^{\mathrm{ns}}$ & $23.84^{* *}$ & $18.29^{* *}$ & $18.24^{* *}$ & $0.57^{\text {ns }}$ \\
\hline$G^{*} S D$ & $2.067^{*}$ & $4.78^{* *}$ & $3.13^{* *}$ & $1.25^{\mathrm{ns}}$ & $1.02^{\text {ns }}$ & $2.012^{*}$ & $1.59 \mathrm{~ns}$ & $1.84^{*}$ & $0.69^{\text {ns }}$ \\
\hline Source & PWP & NSPo & NSP & $1000 S W$ & GYP & GY/ha & SY & $\mathrm{HI}$ & \\
\hline Genotype (G) & $1.06^{\mathrm{ns}}$ & $2.39^{* *}$ & $1.84^{*}$ & $53.75^{* *}$ & $1.45^{\mathrm{ns}}$ & $6.76^{* *}$ & $1.63^{\text {ns }}$ & $2.09^{*}$ & \\
\hline Sowing date (SD) & $0.05^{\text {ns }}$ & $20.64^{\star *}$ & $1.05^{\mathrm{ns}}$ & $48.83^{\star *}$ & $1.72^{* *}$ & $335.41^{* *}$ & $2.56^{\mathrm{ns}}$ & $0.44^{\mathrm{ns}}$ & \\
\hline$G^{*} S D$ & $0.62^{\text {ns }}$ & $0.83^{\text {ns }}$ & $0.79^{\text {ns }}$ & $5.33^{* *}$ & $0.73^{\text {ns }}$ & $5.69^{* *}$ & $1.37^{\mathrm{ns}}$ & $1.41^{\mathrm{ns}}$ & \\
\hline
\end{tabular}

*, ${ }^{* \star}$ Significant at 0.05 and 0.01 probability level, respectively. ns: non significant.

Table 4: Estimates of mean and range for 17 agro-morphological traits in elite lines of lentil sown at timely (TSD) and late sowing (LSD) dates.

\begin{tabular}{|c|c|c|c|c|}
\hline \multirow{2}{*}{ Parameters } & \multicolumn{2}{|c|}{ Mean } & \multicolumn{2}{|c|}{ Range } \\
\hline & TSD & LSD & TSD & LSD \\
\hline Number of days until flowering (NDF) & 111.2 & 91.6 & $87.3-99.7$ & $108-119$ \\
\hline Plant height at flowering (PHF) & 28.1 & 21.9 & 19.3-25 & $22.3-35.3$ \\
\hline Number of days until maturity (NDM) & 160.4 & 122.3 & $157-166$ & $117-130$ \\
\hline First pod level (FPL) $(\mathrm{cm})$ & 18.1 & 14.9 & $11.3-26.7$ & 11.3-20.8 \\
\hline Biological yield per plant (BYP) & 3.6 & 4.3 & $1.95-8.1$ & $1.6-6.4$ \\
\hline Number of branches per plant (NBP) & 3.8 & 2.6 & $2.3-8$ & $2-3$ \\
\hline Number of productive branches per plant (NPBP) & 3.5 & 2.5 & $2.3-7$ & $1.7-3$ \\
\hline Number of pods per inflorescence (NPI) & 3.2 & 2.7 & 2.3-3.7 & $2-3.7$ \\
\hline Number of pods per plant (NPP) & 27.2 & 29.8 & $14.3-44.3$ & $10.7-53.7$ \\
\hline Pod weight per plant (PWP) & 1.3 & 1.2 & $0.6-1.8$ & $0.4-2.1$ \\
\hline Number of seeds per pod (NSPo) & 1.5 & 1.1 & $1-2$ & $1-1.7$ \\
\hline Number of seeds per plant (NSP) & 30.6 & 26.6 & $16-45.3$ & $6-53.3$ \\
\hline 1000 seed weight (1000SW) (g) & 39 & 44 & $29-56$ & $35-60$ \\
\hline Grain yield per plant (GYP) (g) & 1.01 & 0.8 & $0.38-1.4$ & $0.2-1.6$ \\
\hline Grain yield per ha (GY/ha) (Kg) & 522.8 & 117 & $66.3-848.3$ & $9-258.7$ \\
\hline Straw yield per plant (SY) (g) & 3.2 & 2.5 & $1.5-6.7$ & $1.3-4.6$ \\
\hline Harvest index (\%) (HI) & 27 & 25 & $9-44$ & $9-38$ \\
\hline
\end{tabular}


affects grain yield, seeds weight and number of pods per plant of lentils. Significant variation in the number of seeds per pod suggests that pod fertility is a predominant trait and appears to be under genetic control as suggested by Mathura et al. (2006) and Million (2012). Harvest index is defined as the degree of translocation of assimilate to seeds. It shows efficiency in distribution of photosynthetic products into grain in plants. Our study showed a genotype effect on the harvest index. The lowest harvest index was obtained in case of late-sowing date (for L1 and L2 lines).

Information on nature and magnitude of association among different traits can be helpful in indirect selection of desirable traits with low heritability, simultaneous selection of several traits (Singh, 1972) and to avoid undesirable correlated changes in desirable traits during selection (Tyagi and Khan, 2010). Correlation study between grain yield per plant and its components traits (Table 5 ) viz., plant height at flowering $(r=0.34)$, biological yield per plant $(r=0.35)$, the number of branches per plant $(r=0.4)$, the straw yield per plant $(r=0.23)$ and the number of days to flowering $(r=0.23)$ were found major yield contributing traits and can be given due emphasis during development of improved genotypes of lentil for rainfed condition of Tunisia. This important correlation between yield and the various parameters indicates that the yield is a quantitative multi-gene trait. Indeed, the selection for yield can lead to different effects on the other characters, so the selection of one character induces that of the other. These correlations are therefore tools for selecting traits in varietal improvement program.

Principal component analysis (PCA) reflects the importance of the largest contributor to the total variation at each axis of differentiation and also identifies plant traits that contribute most to the observed variation within group of genotypes. Results showed that the first two axes of the principal component analysis (PCA1 and PCA2) explained $66.9 \%$ of the total variability, with respectively $44.21 \%$ and $22.71 \%$. Based on the principal component analysis, lentil genotypes were divided to 4 groups (Fig 1). The first group is positively correlated with the first two axes. This group is composed by L2, L5, L6, L9 and L15 lines. The second group is positively correlated with the first axis and negatively correlated with the second axis. It is composed by L1, L13 and L14 lines. The third group, composed by L3, L7, L8, $\mathrm{L} 10, \mathrm{~L} 11$ and L16 lines, is negatively correlated with the first axis and positively correlated with the second axis. The fourth group gathered L4 and L12 lines is negatively correlated with the first two axes.

Results presented in (Table 6) showed that axis 1 is positively correlated to pod weight per plant (P8) $(r=0.93)$, grain yield per plant (P11) ( $r=0.93)$, first pod level (P5) $(r=-0.89)$, number of seeds per plant $(P 10)(r=0.89)$, number of pods per plant $(P 7)(r=0.88)$, number of days to flowering $(P 16)(r=-0.87)$, grain yield per ha (P15) $(r=0.84)$, the number of days to maturity (P17) $(r=-0.83)$, the harvest index (P13) $(r=0.78)$, the plant height at flowering (P1) $(r=-0.5), 1000$ seeds weight (P14) $(r=-0.4)$. Axis 2 is correlated to biological yield

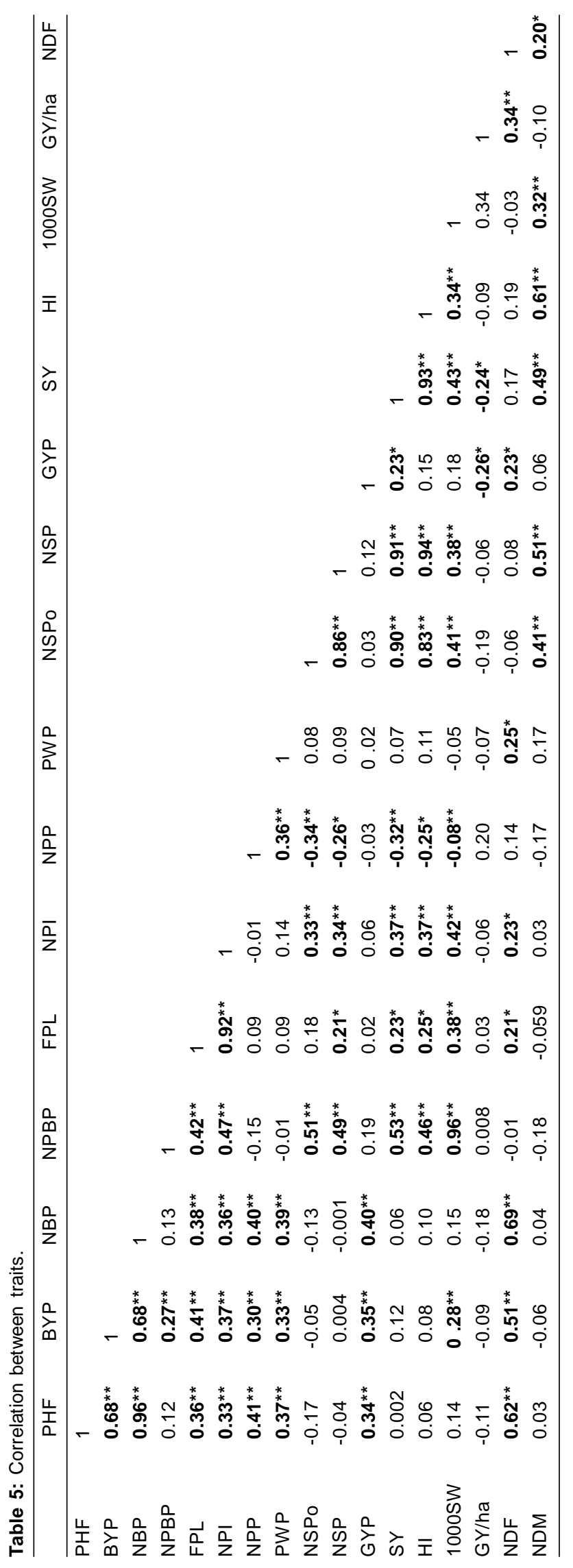




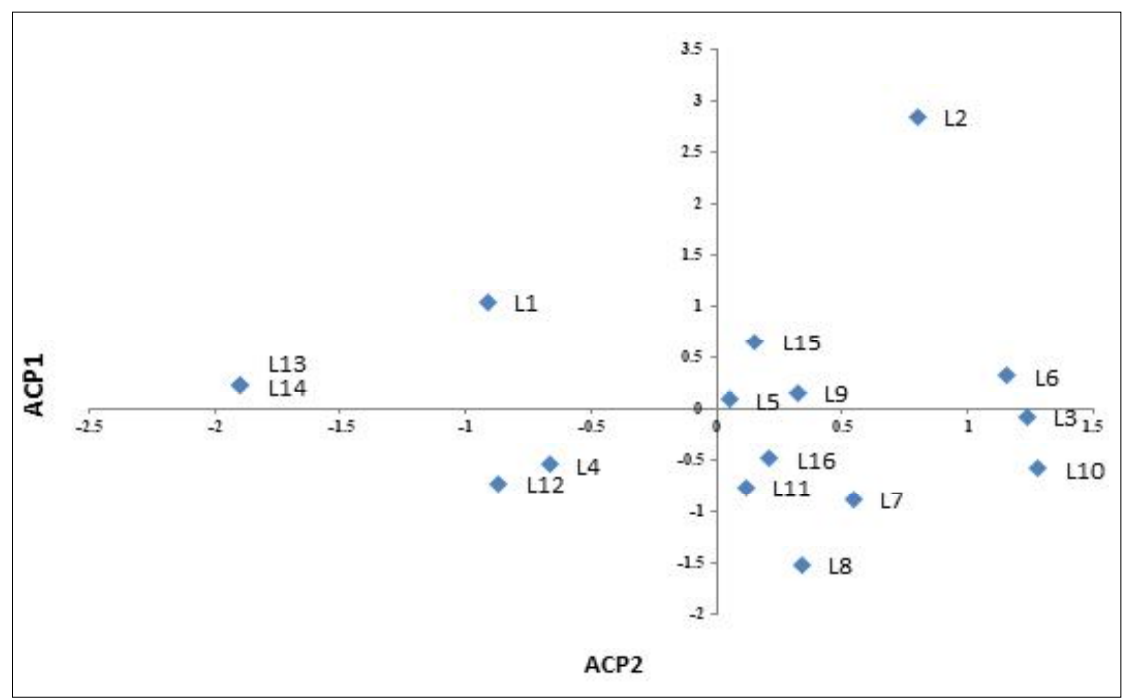

Fig 1: Distribution of lentil lines according to axes 1 and 2 of the principal component analysis.

Table 6: Correlation coefficients for principal components.

\begin{tabular}{lcc}
\hline Parameters & Axe 1 & Axe 2 \\
\hline PHF & $-\mathbf{0 . 5 0}$ & 0.33 \\
BYP & -0.03 & $\mathbf{0 . 8 6}$ \\
BYP & 0.06 & $\mathbf{0 . 8 6}$ \\
NBP & 0.39 & $\mathbf{0 . 7 9}$ \\
FPL & -0.89 & -0.08 \\
NPI & 0.23 & -0.31 \\
NPP & $\mathbf{0 . 8 8}$ & 0.22 \\
PWP & $\mathbf{0 . 9 3}$ & 0.10 \\
NSPo & 0.02 & -0.56 \\
NSP & $\mathbf{0 . 8 9}$ & 0.09 \\
GYP & $\mathbf{0 . 9 3}$ & 0.11 \\
SY & -0.26 & $\mathbf{0 . 8 4}$ \\
HI & $\mathbf{0 . 7 8}$ & -0.48 \\
1000SW & $-\mathbf{0 . 4 0}$ & 0.27 \\
GY/ha & $\mathbf{0 . 8 4}$ & -0.22 \\
NDF & $-\mathbf{0 . 8 7}$ & -0.01 \\
NDM & $\mathbf{0 . 8 3}$ & -0.31 \\
\hline
\end{tabular}

per plant (P2) $(r=0.86)$, number of branches per plant (P3) $(r=0.86)$, straw yield per plant $(P 12)(r=0.84)$, number of productive branches per plant (P4) $(r=0.79)$, number of seeds per pod (P9) $(r=-0.56)$ and number of pods per inflorescence (P6) $(r=-0.31)$. Sharma et al. (2020) also reported the lentil characters that had the highest weight in component first were plot yield, yield per plant, pods per plant, crop growth rate, biomass per plant, leaf area index and plant height.

\section{CONCLUSION}

Based on agro-morphological analysis, lentil lines exhibited considerable genetic variability. The provided information on the variability of the tested material allows us to conclude that the plant material contains a significant potential for improvement. The L2, L3 and L13 lines were shown to be early. They can serve as a source of parents to improve the precocity of varieties. Among the tested lines, L3 line seem to be earliest lines. It showed high yield as well in timely and late sown dates. This line deserves more attention to develop short-cycle and high yielding variety. It will be tested for several years at different sites before being registered in the official catalog of plant varieties. The availability of this early material could increase lentil production and offers the producer an profitable benefit in their cropping systems.

\section{REFERENCES}

Abd-Rahman, M.M., Tawaha, M. and Turk, A. (2002). Effect of dates and rates of sowing on yield and yield component of lentil (Lens culinaris Medik) under semis arid condition. Journal Bio Science. 5: 531-532.

Arumuganathan, K. and Earle, E.D. (1991). Nuclear DNA content of some important plant species. Plant Molecular Biology. 9: 208-218.

Gautam, N.K., Singh, N., Iquebal, M.A., Singh, M., Akhtar, J., Khan, Z. and Ram, B. (2014). Genetic diversity analysis for quantitative traits in lentil (Lens culinaris Medik) germplasm. Legume Research. 37: 139-144.

Gautam, N. K., Bhardwaj, R., Yadav, S., Suneja, P., Tripathi, K. and Ram, B. (2018). Identification of lentil (Lens culinaris Medik.) germplasm rich in protein and amino acids for utilization in crop improvement. Indian Journal of Genetics. 78: 470-477.

Mathura, R., Verma, R., Kumar, V. (2006). Multivariate genetic analysis of pea (Pisum sativum L.). Vegetable Science. 33: 149-154.

Matthews, P., Mc Caffery, D. (2011). Winter Crop Variety Sowing Guide. NSW DPI Management Guide.

Million, F. (2012). Variability, heritability and association of some morpho-agronomic traits in field pea (Pisum sativum L.) genotypes. Pakistan Journal of Biological Sciences. 15: 358-366. 
Selection of Lentil (Lens culunaris L.) Lines Grown at Different Sowing Dates for Their Precocity and Their Agronomic...

Sen, S., Ghosn, M., Mazumdar, D., Saha, B., Dolui, S. (2016). Effect of sowing date and variety on phenology and yield of lentil during rabi season. Journal of Crop and Weed. 12: $135-138$

Sharma, S.R., Sarvjeet Singh, R.K. Gill, Kumar R. and Parihar, A.K. (2020). Selection of promising genotypes of lentil (Lens culinaris Medik.) by deciphering genetic diversity and trait association. Legume Research. 43: 764769.

Shrestha, R., Turner, N.C., Siddique, K.H.M., Turner, D.W., Speijers, J. (2006). A water deficit during pod development in lentils reduces flower and pod numbers but not seed size. Journal of Agriculture Research. 57: 427-438.

Singh, R.K. (1972). Selection index-yes or no. Vistas in Plant Sciences. 2: 111-140.

Turk, M.M., Tawaha, A.M. and Elshatnaw, M.K.J. (2003). Response of lentil (Lens culinaris Medik) to plant density sowing date, phosphorus fertilization and Ethephon application in the absence of moisture stress. Journal of Agronomy and Crop Science. 189: 1-6.
Tyagi, S.D. and Khan, M.H. (2010). Studies on genetic variability and interrelationship among the different traits in microsperma Ientil (Lens culinaris Medik.). Journal of Agricultural Biotechnology and Sustainable Development. 2: 15-20.

Ugwuoke, C.U., Asogwa, A.A., Okwo, C.R., Onu, F.M., Eze, G.E. and Onah, F.C. (2021). Effects of planting distance and seed rate on the growth and yield of Egusi melon (Citrullus colocynthis). Legume Research. 44: 328-333.

Voisin, A.S. and Salon, C. (2004). Efficience de la nutrition azotée. In: Agrophysiologie du pois protéagineux. [B.V. MunierJolain Na., Chaillet I., Lecoeur J., Jeufrroy M.H., (ed.)], INRA-Arvalis, Paris. p. 94-98.

Yannick, U.S.,Mayele, K., Kasangij, A., Kasangij, P., Nyembo, K.L. and Baboy, L.L. (2014). Effets de la date de semis et des écartements sur la croissance et le rendement du niébé [Vigna unguiculata (L.) Walp] à Lubumbashi, RD Congo. International Journal of Innovation and Applied Studies. 6: 40-47.

Zubair, M., Ajmal, S.U., Anwar, M. and Haqqani, A.M. (2007). Multivariate analysis for quantitative traits in mungbean [Vigna radiata (L.) Wilczek]. Pakistan Journal of Botany. 39: 103-113. 